Article

\title{
Understanding Landscape Identity in the Context of Rapid Urban Change in China
}

\author{
Yuhan Shao ${ }^{1} \mathbb{D}$, Eckart Lange ${ }^{2} \mathbb{D}$, Kevin Thwaites ${ }^{2}$, Zhenying Xue ${ }^{1}$ and Xinyu $\mathrm{Xu}^{1, *}$ \\ 1 Department of Landscape Architecture, Shanghai Key Laboratory of Urban Renewal and Spatial \\ Optimization Technology, College of Architecture and Urban Planning, Tongji University, \\ Shanghai 200092, China; shaoyuhan@tongji.edu.cn (Y.S.); 1933726@tongji.edu.cn (Z.X.) \\ 2 Department of Landscape, The University of Sheffield, Western Bank, Sheffield S10 2TN, UK; \\ e.lange@sheffield.ac.uk (E.L.); k.thwaites@sheffield.ac.uk (K.T.) \\ * Correspondence: 1930125@tongji.edu.cn
}

Received: 4 August 2020; Accepted: 25 August 2020; Published: 27 August 2020

\begin{abstract}
China is one of the most rapidly urbanising countries in the world. In recent years, it has experienced enormous environmental changes, as well as a loss of landscape identity. This paper aims to explore the concept of landscape identity in the context of the overwhelming urbanisation in China. It develops a conceptual framework on landscape identity from different dimensions. Factors are also identified that drive the urban changes with regard to the landscape identity that develops over time. Taking the city of Yantai, a city in Shandong Province, as an example, it is demonstrated how this conceptual framework can be applied to help in the understanding and protection of landscape identity in China.
\end{abstract}

Keywords: landscape identity; urban environment; conceptual framework; rapid urbanisation

\section{Introduction}

In the studies on the history of landscape development and its cultural value assessment, landscapes are viewed as complex representations of continuous interactions between people and their surrounding environment, influenced by different factors in the processes of the environment's evolution [1-5]. Landscape identity, which makes the landscape of one place different from that of another, is not fixed, but rather a dynamic process that evolves with time, based on the human-environment relationships [6,7]. However, such change may stimulate feelings of misunderstanding, as well as disorientation and even threat, leading to a loss of connectivity and an affinity between the inhabitants of the landscape and the settings that they use [8,9]. Because different landscape contexts have different identities, such identities would also afford different meanings to such settings. Hence, it is important for both academics and practitioners to recognise this subjective aspect of landscape identity in real-life projects. However, with the development of globalised cities, the pursuit of efficiency takes precedence over the connection between the city and its residents, resulting in drastic changes and the neglect of the urban landscape identity, which is a common problem that global cities are all facing. This is especially true in China, where cities grow so fast; changes that may take a decade to complete occur within a few years. Moreover, with the speed of modern urban transformation, a lack of understanding of the dynamic nature of landscape identity and an absence of an appropriate and applicable conceptual framework for Chinese urban development is contributing to a loss of landscape identity.

Since the 1990s, many Chinese cities have developed rapidly, following the example of other successful cities worldwide; this has consequently caused inevitable homogenisation of urban form to the point of cities becoming identical. Such extremes can be seen in the Chinese urban developers' adoption of the Soho district from Manhattan as an urban developmental influence, resulting in 
the loss of uniqueness of landscape [10]. As a result, considerable elements that were unique to the cities in China have been lost, while some parts of cities have continued to be redeveloped to replicate developed countries [11]. This phenomenon has obviously obliterated valuable landscapes (landscapes that have special meanings to local residents and history) [12]. This is an outcome of the contemporary approaches to Chinese urban development, driven mainly by the priorities of creating a cityscape. Such priorities have led to the view that building new skyscrapers, which have outstanding appearances, is a primary solution, rather than reflecting on conserving the uniqueness of the city by means of responding to the existing landscape heritage or rearranging the current urban identity [13].

This paper aims to respond to landscape identity by investigating it in the contemporary context of the rapid urban development in China and to develop a conceptual landscape identity assessment framework that can be applied to benefit urban planning and design in practice. This is significant in the context of Chinese urban development in providing potential for Chinese urban developers to better protect and improve their landscape identity in a continuously changing Chinese urban environment.

The objectives of this paper are to:

- Review the literature of landscape identity in relation to the Chinese urban development context, which exemplifies the problem of loss of landscape identity in Chinese cities.

- Develop a conceptual framework to help practitioners gain better knowledge of the term in contemporary Chinese urban development practice.

- Carry out interviews using the conceptual framework to assess landscape identity in Yantai; these interviews will also serve as a verification of the feasibility and applicability of this framework.

The outcome of the paper will be to:

- Present a better explanation of the definition of landscape identity and its conceptual framework relevant to the context of the urbanisation in China.

- Suggest the practicality of the study's results concerning the loss of landscape identity in Chinese city development.

Through such a case study, the importance of understanding landscape identity relevant to the context of Chinese urban development is discussed, from which a conceptual framework is developed. This will have the potential, when further developed and empirically studied and upgraded, to be beneficial for Chinese urban and landscape designers to understand and evaluate landscape identity. It is also likely to play an important role in decision-making.

\section{Understanding Landscape Identity in Chinese Urban Development}

Landscape identity in this paper represents landscape appearance at small-scale places, such as city quarters or the street level, to provide features that create a recognisable image of the place and its residents to differentiate from other places. It provides special feelings through physical, social, sensory and memory perspectives; such feelings include both positive and negative emotions. This section introduces the core research problem and reviews the relevant literature to: gain a deeper understanding of the term landscape identity and form a conceptual framework that is responsive to China's problem of landscape identity loss.

In the last ten years, globalisation has affected the physical development of cities. During the process of modernisation, China has adopted paradigmatic urban planning approach and design elements without adequate analysis and localisation [14]. Thus, disorder and imbalance in the cityscapes have emerged while the urban tradition has been terminated [11]. Medium- and high-rise buildings have been abruptly introduced to Chinese cities, and natural elements have been sacrificed for roads and other infrastructure required by contemporary urban development [15]. This has destroyed a lot of traditional public spaces that previously acted as the intermedia for local culture, eliminating much of the neighbourly human contact. Furthermore, local elements that have significant historical meanings and heritages have also been destroyed due to such modernisation. The earlier colonisation 
(more detail in Appendix A), the subsequent modernisation and the now overwhelming globalisation have led to the disruption of historical, cultural and social structures, which may be one of the two main reasons for the progressive loss of landscape identity in Chinese cities, while the apathy of city dwellers towards the tangible and intangible urban heritage may be the other [12]. Therefore, it is demanding but important to protect, improve and even create landscape identity in the contemporary context of rapid urban development in China, as it expresses the uniqueness of the city that makes it distinguished among many cities.

Landscape is also considered from the past to the future; historical and future considerations have also played an important role in defining landscape identity. Among those Chinese cities experiencing problems with regard to loss of landscape identity, Yantai has been typical. A typical example of how Yantai lost an aspect of its landscape identity is the government's decision to convert its famous golden-white sand bay into a central-square landmark. In 2003, the Binhai Square was approved by the Yantai government in order to create a city parlour and provide space for large events for the citizens, as well as complete the construction as a political achievement. Although the construction of this area was based on the protection of old buildings and their surrounding environment and continuation of historical context, little attention was paid to the context of nature; the coastline of the beach has been notably changed into artificial terraces. Meanwhile, high-rise buildings have sprung up around the area. Local social activities such as swimming, fishing and other beach activities have thus vanished. Although non-local visitors see the square as a good place from which to view the sea, local people express nostalgia for the old days when they could 'interact' with the sea and the beach (Figure 1).

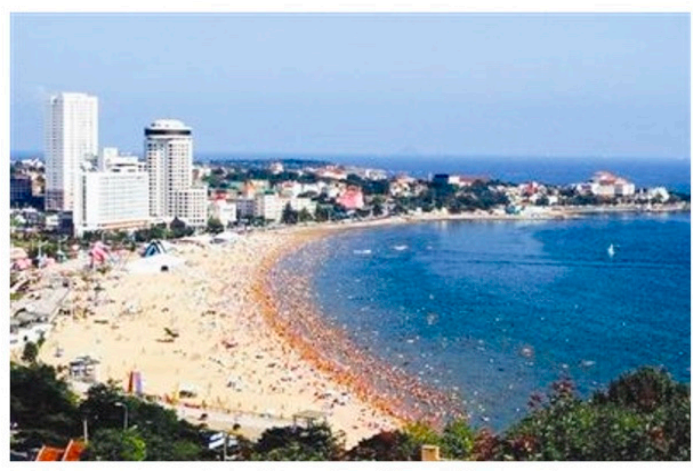

Pre-Reconstruction of Yantai Golden White Sand Bay

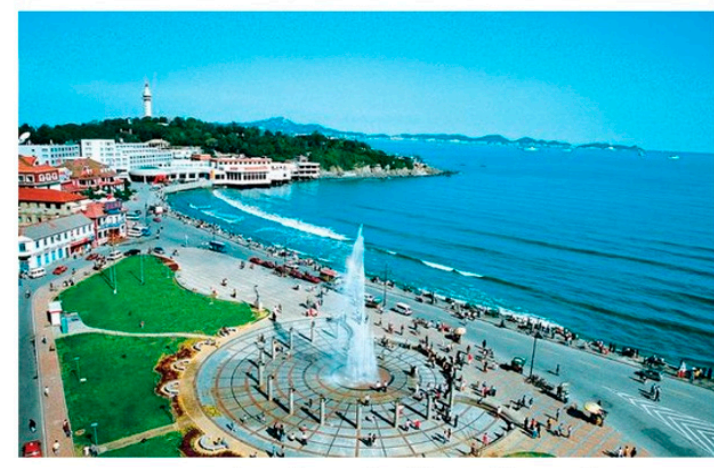

Post-Reconstruction of Yantai Golden White Sand Bay

Figure 1. Pre- (2003) and Post-Reconstruction (2015) of Yantai Golden Withe San Bay (Yantai City Planning Exhibition Hall). In 2003, the natural shoreline of the sandy bay was replaced by a man-made plaza.

From the perspective of the users of the landscape, as people contribute to landscape identities from social and cultural perspectives, landscape identity has been seen to unite inhabitants and distinguish them from those from other areas by local residents [16]. Lynch [17] and Proshansky [18] highlight the importance of interaction between people and the landscape, pointing out that the identity created through such interaction provides value to support people's lives. However, China's landscape identity problem not only relates to the physical side of the environment, but also to the balance between society and the relevant physical appearance. As such, Korpela [19] tried to focus more on the social contribution of landscape identity. He concluded that memory and time experience with the local landscape have a great impact on people's self-esteem and sense of coherence in the local community. Cuba and Hummon [20] also analysed how different social and environmental factors discriminate identification characteristics across the landscape from the aspects of local dwellings, community and the region. The example of the golden-white sand bay in Yantai described above explicitly shows the impact that changing the physical appearance has had on the local people's social dwelling and community. 
Apart from the physically related aspects of landscape, history is also an important factor that contributes to landscape identity. Devine-Wright and Lyons [21] and Paasi [22] all discussed the significance of historical heritage from both place and society memory in terms of constructing landscape identities. They point out that peoples' identity is shaped through spiritual interaction with many intangible aspects of landscape environments, which varies from person to person due to his social and demographic attributes such as social class, religion, ethnicity and gender. With regard to relations between landscape appearance and society, Jorgensen et al. [23], assessed local people's perceptions of the aesthetic and community aspects of the local landscape, suggesting that their satisfaction and living experience makes a strong contribution to the formation of the identity, which also increases the attachment felt by local residents. Other research emphasises how valuable landscape characteristics impact the formation of personal behaviour and local culture [24,25]. Yantai also shows how a change of historical landscape appearance impacts on local people's memory and their satisfaction levels.

\subsection{Aspects of Landscape Identity}

From the Yantai example, we can see that there are multiple aspects of landscape identity: physical impact, social meanings and society and cultural constructions. Similarly, Loupa Ramos et al. [26] proposed a transactional model of landscape identity underlining the importance of both the physical landscape and people's perception. This mutual and dynamic interaction is characterised by two levels: a sphere of perceptions, which refers to the perceived character of a landscape as a mentally constructed entity [27], and a sphere of action, which describes how the landscape and society interact with actions that might stimulate bonds between the people and their surroundings [8,28]. However, with regard to the loss of landscape identity in China, it is not sufficient to only analyse the term from a single aspect: a dynamic, conceptual framework that identifies the inter-relationships between all the perspectives of landscape identity is required. Such a framework needs to show the impacts of each aspect on the others and be able to reveal all the relationships and the features of each aspect.

Physical and Spatial Aspects: Gualtieri [29] and Mansvelt and Pedroli [30] declared 'place identity' to be the basic physical-human interaction between people and the physical environment. The broad sense of the physical world includes both the physical properties of the settings and the involvements, memories and symbolic meanings. It is identified to be an intrinsic quality of people's perceptions of landscape [31-33]. How people ascribe identity to their environment has been described as landscape character [34,35] or landscape identity [36]. The main focus here appears to be on the spatial scale. Such spatial characteristics have been divided into place identity and regional identity levels [37], with place identity referring to a smaller scale in the landscape, particularly to striking unique or historical objects that attract people's attention, for example church towers, farms and rivers. Regional identity refers to the larger scale and is more attached to geographical, natural and cultural heritage.

Social and Cultural Aspects: early studies $[38,39]$ introduced personal identity as a philosophical concept in the 1970s. Originally, the term related to how people recognise one another by their appearance, e.g., their physical appearance, their voices or how they behave. It is also recognised as a bond to personal history and experiences [40]. In later years, personal identity was oriented to the field of landscape architecture by a further research study by Proshansky [18], which redefined personal identity as how the inhabitants of landscapes perceive physical settings around them that are derived from the aspects of the physical world described above and life experiences of their own. A common definition of personal identity in landscape research field is the perception of an individual interacting with the physical characteristics of the place [18,41]. Belk [42] and Sack [43] also described it with embodiment of phenomena related to the people in some kind of environment, such as the roles people play in the place, the groups to which they belong and the concrete places in their mind. Culture is important to the formation of landscape identity. The study of Oktay [44] noted that it is not enough to just walk in the streets and squares to learn about a place; participating in the lives of the local residents is also necessary. Culture plays an indispensable role in the formation of local 
characteristics and identity. A later study by Krause [45] focused on two sides of the landscape, the spatial and structural characteristics, as well as the cultural aesthetic expressions, both of which are relevant to the development of landscape identity. The landscape identity of a city includes not only the culture of the city but also its uniqueness in the regional environment. Specifically, the history of the city, including but not limited to its events and people, also influences and participates in shaping the identity of the city $[46,47]$.

Based on the core aspects identified, we have found that the framework introduced by Stobbelaar and Pedroli [48] is particularly useful in developing a conceptual framework of landscape identity for Chinese urban development. They consider landscape identity as the unique psycho-sociological perception of a place defined in a spatial-cultural space. They introduced four different identity terms that contribute to such perception as: existential, spatial, personal and cultural identities; and also established a distinct, specific differentiation between the terms:

- Existential Identity is more concerned with the physicality that people perceive in their local place.

- Spatial Identity is based on the view that people identify landscapes by their characteristics of forms, patterns and elements, and is more concerned with the way people's identity associates with their environment [49].

- Personal Identity is more concerned with the feeling of one person in a particular place on their own.

- Cultural Identity is about some kind of narrative that is derived from people's consensus of local landscapes.

The four identities capture the essence of landscape identity that is especially relevant to the context of Chinese landscape identity. As described in the first paragraph of this section, they interact dynamically to influence both landscape identity and people's perception of the physical landscape from two aspects: sphere of perception and action. Therefore, it is not sufficient to only evaluate the four identities separately in the context of exploring the Chinese landscape identity. Hence, for this to be developed into a conceptual model with the potential for application, this essence and the dynamic interaction needs to be expressed in terms of the four identity relationships. These provide the foundations upon which to develop a provisional conceptual framework for application to the research problem:

- Personal-Existential: in this relationship, the personal meanings of a landscape lie in the associations and memories attached to the landscape [50,51]. Such self-identity should continuously be confirmed and changed through the interaction between people and their social and physical environments [21,52-54].

- Cultural-Existential: a place can help people to sense the mutual connection between themselves by means of envisaged images of a collective future, hence forming a community that shares similar inter-personal values [55]. Through such processes, places are used by local populations for celebratory, commemorative or recreational activities, creating a new culture in the community which is regarded as important to their society's characteristics [56,57].

- Cultural-Spatial: this relationship focuses on the features that distinguish one region from another [58]. In such a perspective, physical features can be observed by everyone, such as spatial composition, vegetation and wildlife.

- Personal-Spatial: such interaction emphasises the importance of the landscape for an individual's recognition and his means of orientation within it. Such identity relates to the features of the landscape's physical appearance that can be observed by everyone, but which are not of equal importance to everyone [17,59].

\subsection{Identification of Landscape Identity in Chinese Urban Development}

The four identity relationships have representational power for different purposes on different stakeholders under different circumstances. However, challenges remain when it comes to the 
identification of landscape identity through such inter-relationship models, as it could be confusing when asking a participant to identify a relationship in real-life projects. In essence, how are we going to identify such relationships in real-life practical projects? Research that aims to provide answers to evaluating landscape identity through such relationships is interview-based. To make this achievable with non-specialist participants, the relationships are translated into more visualised, noticeable and recordable aspects that can be obtained through social research methods, e.g., participants' interviews. It can be seen that each identity relationship has its own focus: the personal-existential is focused on the sensory feeling that people have through their interaction with the surrounding environment; the cultural-existential emphasises the reflection of local cultural and historical factors; the cultural-spatial focuses on the meanings of culture and history embedded in people's memory, and how such memory affects local environment through human-environment interaction; and the personal-spatial reflects the importance of the landscape's physical appearance in providing people with their meanings. This paper, therefore, will use physical, social, sensory and memory aspects as reflections of the relationships described above. The reasons are:

- Physical Aspects (Personal-Spatial): in all the relative identities, it is clear that physical aspects are a major aspect of landscape identity and act as the major medium that reflects the personal-spatial identity relationship [60]. The main focus is on the physicality that people perceive and the gratification they gain in their local place $[17,48,59]$. Thus, of all the identities, physicality is the most basic to explore. The term physical aspect is used to describe the surrounding geographical features, as well as other visible and concrete embodiments in the local environment, such as the way the place is formed and the style of architecture. Most importantly, it acts as the medium through which people interact with the surrounding environment. The physical aspects mainly consist of the architectural environment and the landscape environment. For example, this includes housing types and settlement patterns.

- Social Aspects (Cultural-Existential): the inhabitants of the urban landscape are essential. The significance of social activities in the process of the identification and evaluation of community identities was demonstrated by Tajfel [61] in 1978, whose study developed the idea that social aspects of landscape identity are the synthesis of certain associations in people's daily lives. These associations are based on people's physical environment, events and place history. The cultural-existential identity relationship focuses on how people contribute to the environment to make it more attractive and distinguishable to the outside world [48]. To some extent, it is because of the specific interrelationship between people and place that a place is given a unique identity $[17,41,62-66]$. Namely, when social activities take place in the landscape, a unique identity is also formed. For instance, an annual festival that takes place only in a particular region is often regarded as being the cultural identity of the place; that may become a unignorable part with which to assess the landscape identity. Therefore, social aspects become a reflection of the cultural-existential identity relationship in landscape identity.

- Sensory Aspects (Personal-Existential): an individual identifies the landscape within a site as special largely because some events or experiences recorded in their biography are related to the place $[50,51]$. Everyone has their own past life experiences, integrating the local landscape with their own personal meaning that can be referred to as sensory. The personal-existential relationship is reflected through such sensory aspects. The connection with the place can serve as the significance to the sense landscape. As the inhabitants of the landscape are essential, the personal-existential relationship plays a major role in the sense people get from where they dwell. Feelings about daily life and the surrounding environment contribute to the formation of this relationship [65], which is about the ability to provide psychological comfort [67-69]. Hence, sensory aspects focus on the way people identify the place. People's immediate sensory perception of the place endows it with a certain identity, from the source of which it can be concluded that the people who use the place create the specific identity for it. 
- Memory Aspects (Cultural-Spatial): the cultural-spatial relationship focuses on the uniqueness of cultural meanings that derive from people's daily lives. A community living in a particular area for a long period of time generally leaves considerable heritage [70], which includes tangible heritage, such as historical relics and monuments, as well as intangible heritage, such as spirit and history. However, both spiritual and material aspects are fragments and reflections of local history, which is deeply intertwined with and influences local people's memories. One of the easiest ways to determine the uniqueness of communities in history is to examine their cultures [70]. The term culture is largely embedded into, and formed by, people's memory. It has been cast into autobiographical memories [71] and sociobiographical memories [72], where the former is based on the perspective of individual observers, while the latter is based on consensual social narratives. For individuals, since they can absorb and learn pre-birth history from social memories, the interactive relationships between people and their local environment can be developed from shared memories; hence, local culture can be formed $[65,73]$.

With this four-aspects conceptual framework, Stobbelaar and Pedroli's model is developed into visible elements. Taking the personal-existential relationship as an example, the sensory aspect (in the new conceptual framework) not only emphasises people's feelings with regard to the surrounding landscape, but also evolves through time as the intertwining relationship deepens. Hence, this aspect covers personal identity, existential identity and also expresses the personal-existential relationship. Most importantly, for the purpose of this study, it is easy to interview participants, and it is easy for these participants to understand and express their opinions regarding the interview questions. Hence, such a framework has the potential to help practitioners gain a deeper understanding of local landscape identity.

Based on the previous literature review with regard to the context of Chinese urban development, this paper adopts the definition of landscape identity as the result of the mutual interaction between landscape and people, as integrated concepts considering existential, spatial, personal and cultural identities that have inseparable connections. It should also be pointed out that the four aspects of landscape identity can be perceived by users, hence there are two states: positive and negative. But these two are not either/or. In the following field study, we discuss how to view the balance between them and how they work together in a place's landscape identity. The four-aspects framework forms the provisional conceptual framework of landscape identity, and will provide provisional guidelines for practical identification in the Chinese urban development process. To gain a better understanding of landscape identity in urban Chinese cities, the main issue is how to study and identify the local landscape identity in such a way at to not only show the factors that influence local landscape identity, but also to represent the inter-relationships between the factors. With such issues, the new practical four-factor conceptual framework has the potential to address this requirement.

\section{Methodology}

The aim of the paper is to gain a deeper understanding of landscape identity with regard to the context of Chinese urban development, and also to explore how it can be operationalised to help practitioners make better decisions. Hence, the research used interviews to pilot the applicability of the conceptual framework by providing a foundation for the development of an interview-based method of data gathering. Yantai was chosen due to its typical representative nature to the problem of landscape identity loss in China (see Appendix A).

\subsection{Study Site}

To test the efficiency of the four-aspect framework developed, we chose the Yantai Hill area (Figure 2) as the study site due to its strong representation in all the major landscape identity aspects. The replaced sandy bay mentioned above is located in this area. The area is famous for its rich history and diverse physical architecture and cultures ascribed to the settlement of ethnic and foreign 
businesses [74] (Figure 3). Most importantly, the area has been viewed as the pioneer district during the last decade, when Yantai experienced extremely rapid city transformation.

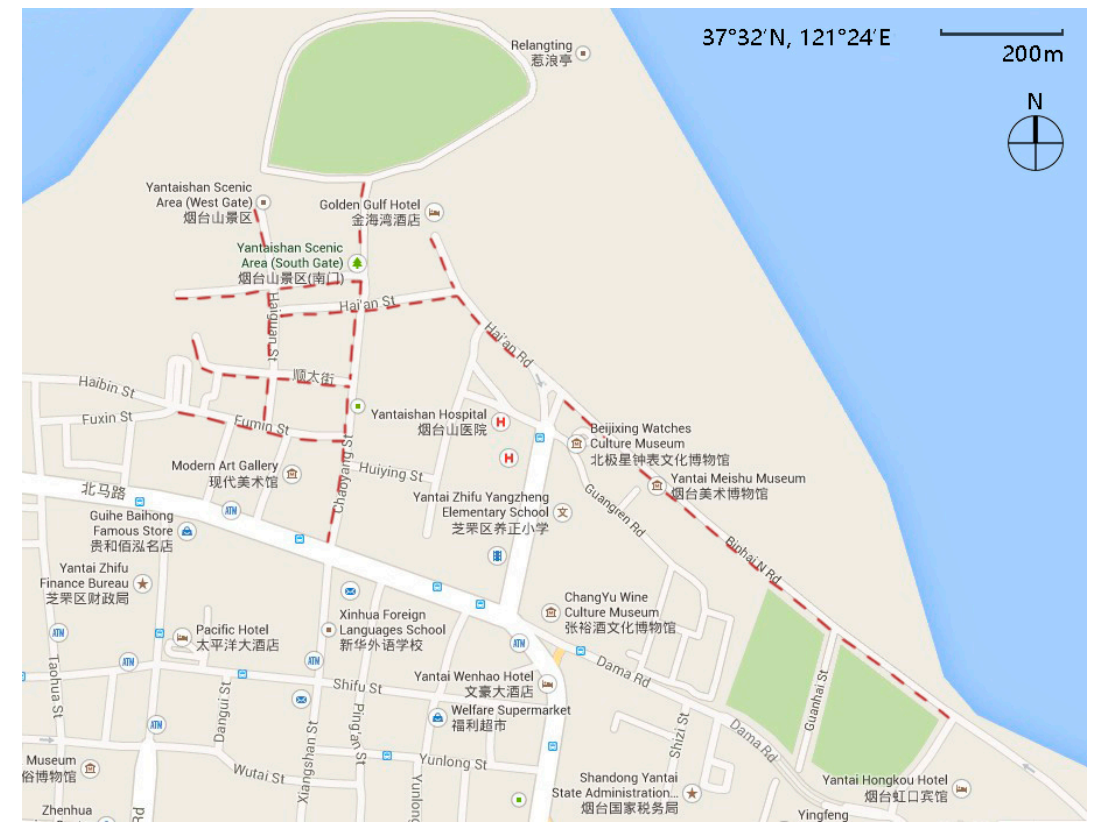

Figure 2. Study site: the Yantai Hill area.

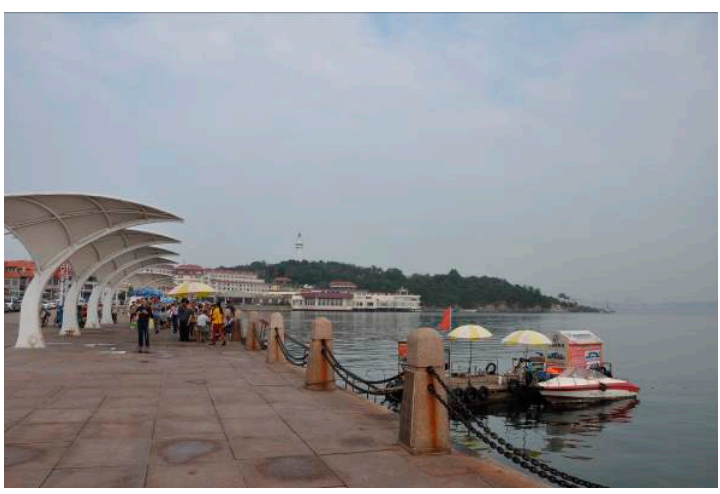

(a)

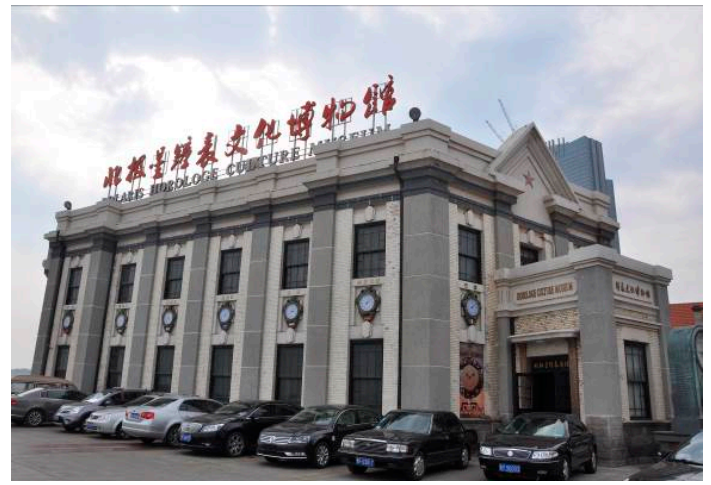

(c)

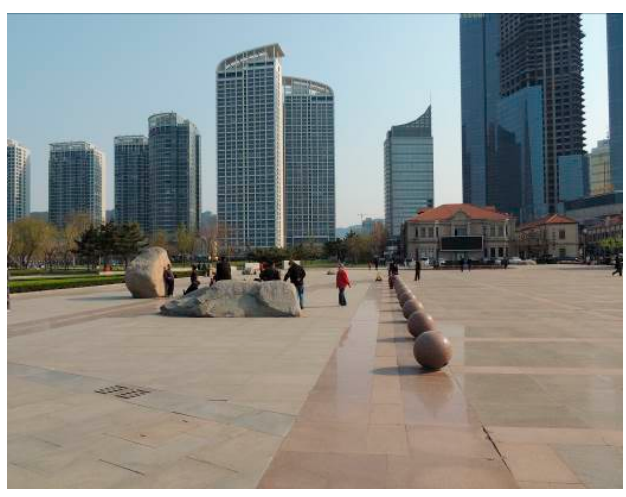

(b)

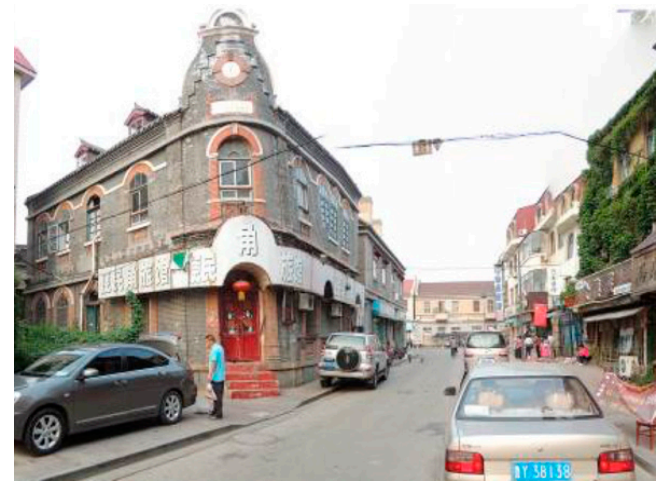

(d)

Figure 3. A glimpse of the Yantai Hill area. They show (a) the artificial terraces of coast, (b) Binhai Square, (c) Polaris Watches Cultural Museum and (d) an old building on Haian Street. 


\subsection{Participant Groups}

Onsite interviews were carried out with local and non-local participants to gather data on the preferences of different participants. Many existing studies show the importance of examining and comparing the preferences of local residents and non-local visitors separately. Even though the landscape is the same, sometimes preferences can vary significantly, depending on how different people react to it [75-77]. It is also common that there is a mismatch between the actual residency and the individual's identity involving a place [78]. This also suggests the necessity of investigating the cognition of the same landscape by different groups participating in local social activities [79].

\subsection{Group Size and Interview Process}

Shinebourne [80] and Watts and Stenner [81] established that, on a normal project of qualitative research, relatively robust data would come from at least 40-60 participants. Therefore, in this study, 50 local residents and 50 non-local tourists were recruited and interviewed on the spot. During the interview process, the participants were guided along the study site and pointed out elements they thought represented the local landscape from the four aspects-physical, social, sensory and memory. They were encouraged to express positive feelings but also to point out elements that made them feel uncomfortable. The elements were recorded on paper and the conversations were recorded using a digital recorder for later analysis.

\subsection{Statistical Analysis}

For later quantitative analysis, the elements that participants mentioned (Figure 4) were categorised into eight groups, according to the semantics: Physical(+); Social(+); Sensory(+); Memory(+); Physical(-); Social(-); Sensory(-); Memory(-). The number of mentions for each of the elements was counted. The proportions of four aspects (Physical, Social, Sensory and Memory) were calculated in both positive(+) and negative(-) dimensions to indicate the characteristics of different landscape identities in these locations. A Hierarchical Cluster Algorithm (HCA) was conducted to classify these locations. The HCA creates a hierarchy of clusters and therefore does not need to pre-specify the number of clusters; the results can be easily visualised using a tree-based representation called a dendrogram [82]. The comprehensive landscape identity assessment of these locations resulted in both positive and negative statistical values. The comprehensive results were ranked to obtain excellent cases in the same category. Both positive or negative landscape identity may catch people's attention, because preferences vary across different groups [75-77]. In order to reveal the relationship between landscape identity and the different groups (local and non-local) who were interested in these locations, correlation analysis was applied between the proportions of different groups and the four aspects (in both positive and negative dimensions). IBM SPSS Statistics 20 was used for data analysis. 


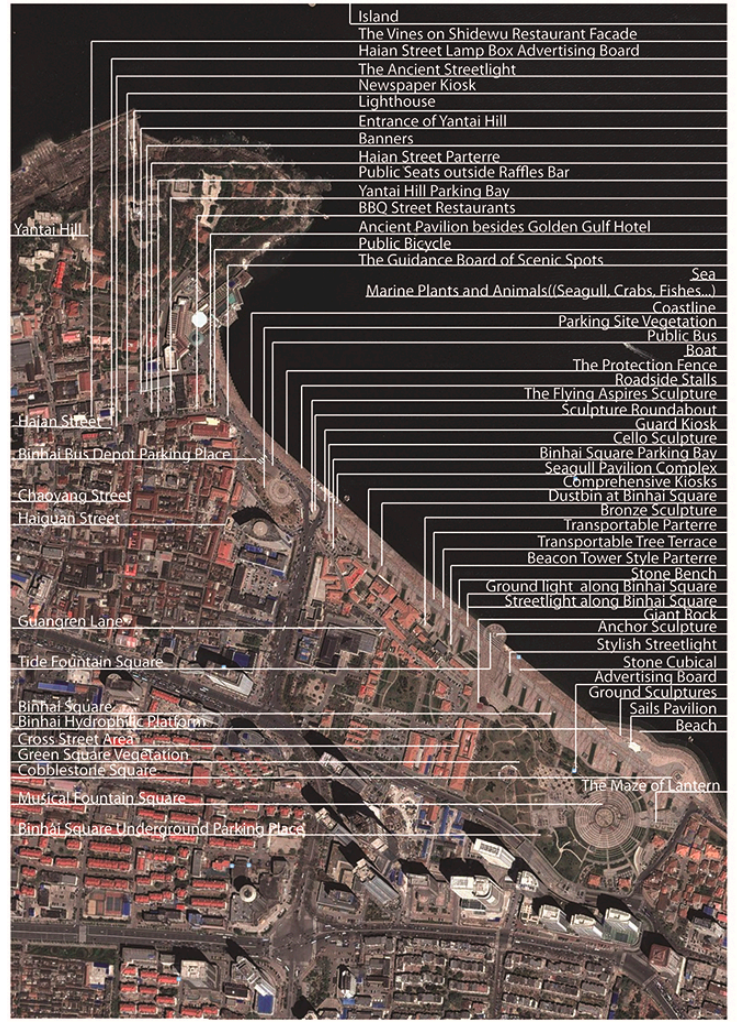

(a)

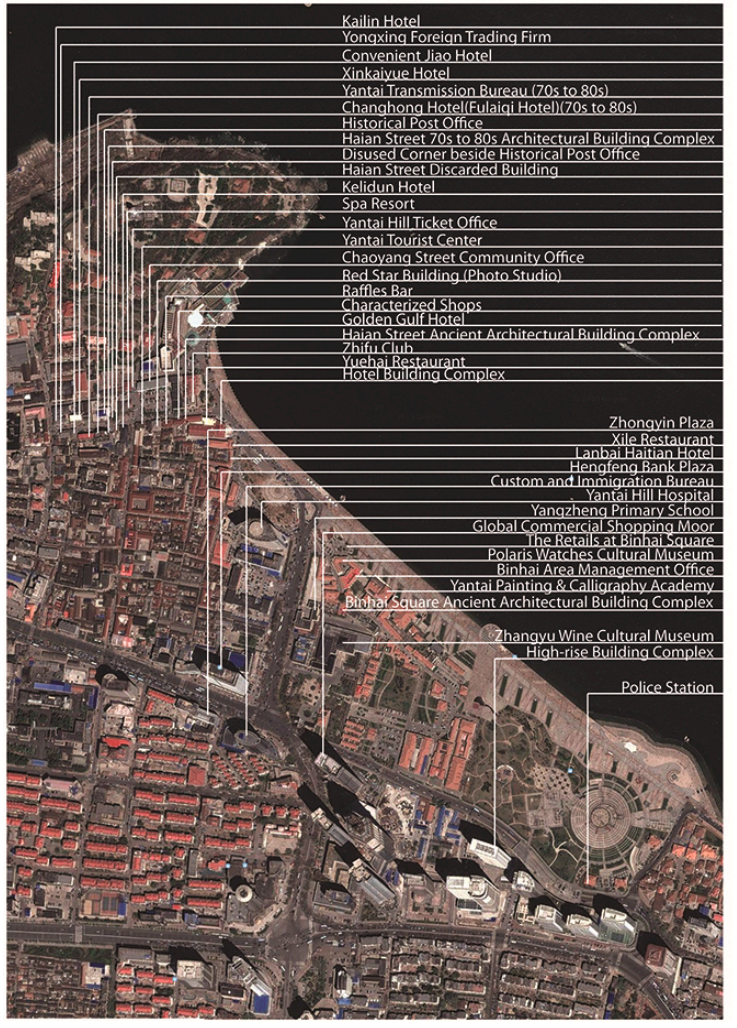

(b)

Figure 4. (a) and (b) show all the elements that participants mentioned during onsite interviewing, some of which were merged by location.

\section{Result}

Based on the elements selected and the reasons for selection, all the participants' opinions were standardised and organised into an overall assessment table for interpolation (Figure 5). Selections of each location were categorised into 'Positive' and 'Negative' opinions (left axis). In each category, the number of participant selections was standardised into a percentage based on the category's total selection. The selection difference between positive and negative opinions was marked using the red line (right axis). For example, with Haian Street at the left end of the table, a red line below 0 (right axis) means more participants viewed this location as a negative landscape identity. Among each category, more than $50 \%$ in the positive selection preferred its social aspect, and around $50 \%$ of the negative opinion focused on its physical aspect. The table clearly visualises the preference at each studied location via the red line, and the proportion bar shows the corresponding contribution that each landscape identity aspect has towards the positive and negative identities.

We then performed an HCA using Ward's Algorithm [83] on the results table to cluster all the studied locations into six different location clusters, A to F (Figure 5). The dotted horizontal line denotes the cut-off for the clusters.

- Cluster A: In this cluster, positive perceptions of landscape identity involved Physical, Social, Sensory and Memory elements, while negative perceptions of landscape identity mainly concentrated on Sensory and Physical aspects. Among these types of locations, people with higher comprehensive evaluation values had fewer or no negative landscape identities, while the four dimensions of positive landscape identities were more average. The landscape included Marine Plants and Animals, Square Ground Sculptures, the Golden Gulf Hotel, the Anchor Sculpture, the Lighthouse, the Binhai Square Architectural Building Complex, the Musical Fountain Square and Zhangyu Wine Cultural Museum. 
- Cluster B: In this cluster, positive perception of landscape identity involved Physical, Social and Memory dimensions, while negative landscape perceptions mainly concentrated on the Memory element. Among these types of places, people with higher comprehensive evaluation values perceived many positive social landscapes. The landscape included Chaoyang Street, the Cross Street Area, Guangren Lane, the Haian Street Ancient Architectural Building Complex and Binhai Square.

- Cluster C: In this cluster, Social aspects dominated the landscape identity, regardless of whether the perception was positive or negative. On the other hand, the larger the proportion of the Sensory aspect, the higher the comprehensive evaluation value. The landscape included the Seagull Pavilion Complex, the Beach, Yantai Hill and the Sea.

- Cluster D: In this cluster, Physical aspects dominated the landscape identity with both positive and negative perceptions. The overall evaluation of this part was low.

- Cluster E: In this cluster, positive landscape perception was mostly Physical and Social elements, while negative landscape perception was based on the Physical aspect. Among these types of locations, places with a large proportion of positive Social perceptions were also relatively highly evaluated. The landscape included the Sails Pavilion, the Stone Cubical and the Coastline.

- Cluster F: In this cluster, very few positive landscape identities could be identified. A small number of recognised landscape identities were Physical, and all negative landscape perceptions were Physical aspects. Among such locations, the overall evaluation was low, and the slightly better locations (the Kelidum Hotel, the Historical Post Office and the Tide Fountain Square) all involved two or more types of landscape aspects in the positive landscape identification.

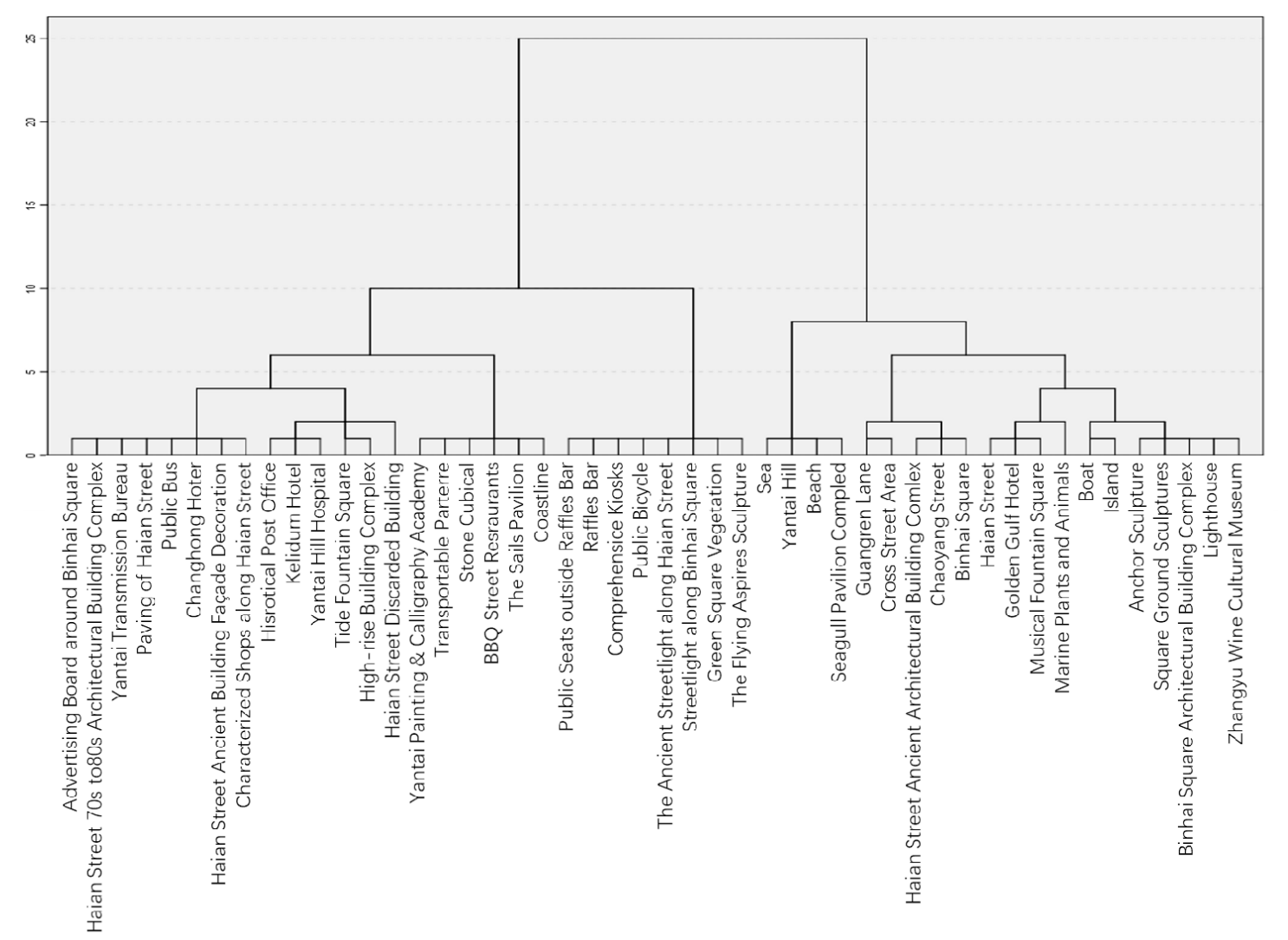

Figure 5. Hierarchical Cluster Analysis.

One of the advantages of this overall assessment table (Figure 6) is the clarity of the importance of each element in embodying the landscape identity, which can be judged by the location of the red line on the chart. The vertical bar charts show which of the four aspects of landscape identity the 
positive and negative assessments of the different places focused on. Hence, the table clearly presents the results of the identification and assessment of landscape identities.

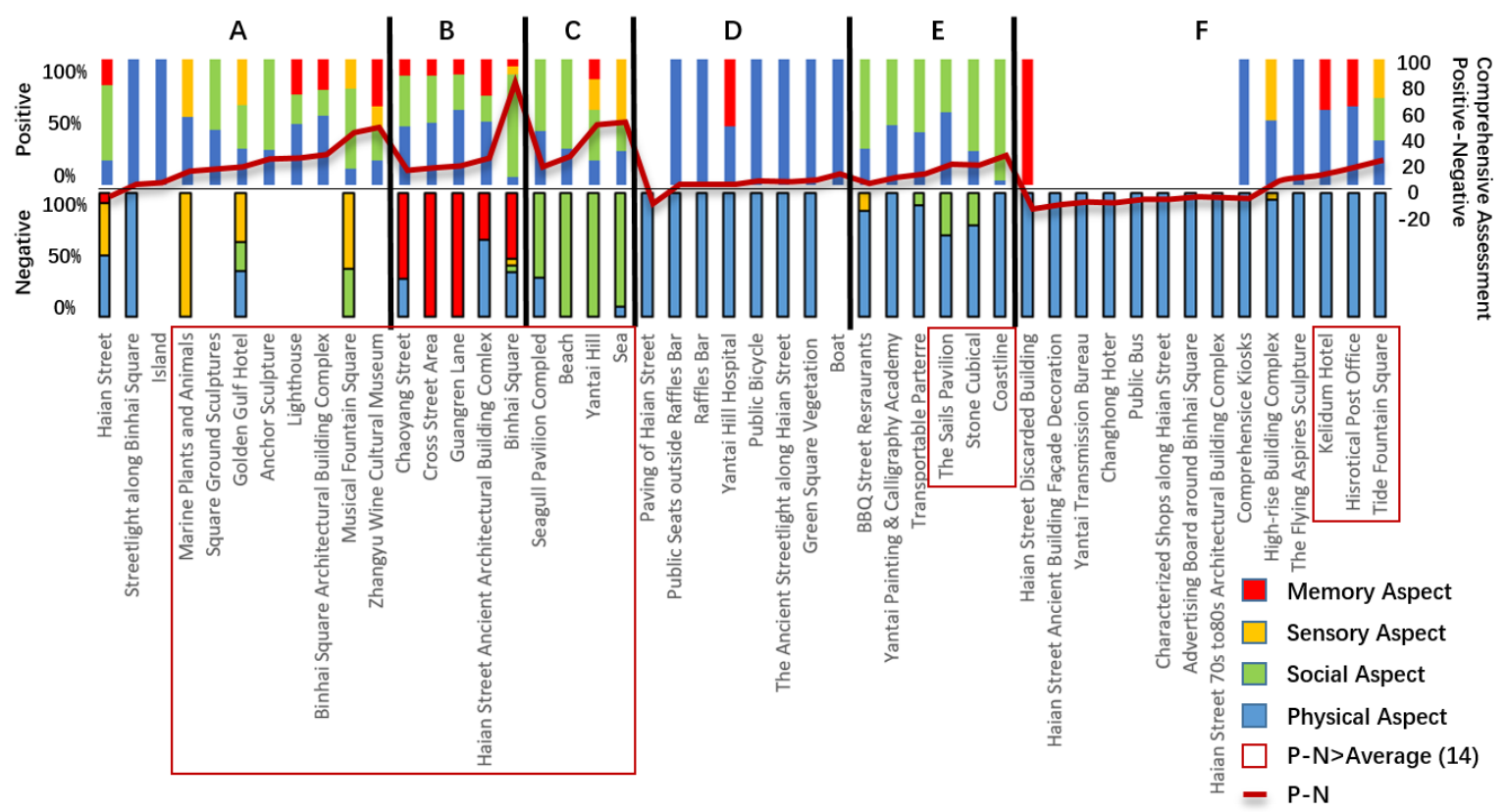

Figure 6. Overall Assessment Table.

Apart from the overall assessment of landscape identity, for all 48 different locations, a Pearson's Correlation analysis was carried out on the percentages of each preference category (positive/negative) and participant groups with different backgrounds (local/non-local) (Table 1). The results show that Memory aspects are significantly correlated with positive landscape identity for local participants. Among these 48 locations, the higher the proportion of local people in the sample of participants, the more positive landscape identities are related to the Memory aspects. Apart from this, the other items have no significant correlation. This shows that memory is an important factor for local residents to perceive landscape identity.

Table 1. Correlation Table.

\begin{tabular}{|c|c|c|c|c|c|c|c|c|c|}
\hline & & \multicolumn{4}{|c|}{ Positive } & \multicolumn{4}{|c|}{ Negative } \\
\hline & & $\begin{array}{l}\text { Physical } \\
\text { Aspect }\end{array}$ & $\begin{array}{c}\text { Social } \\
\text { Aspect }\end{array}$ & $\begin{array}{c}\text { Sensory } \\
\text { Aspect }\end{array}$ & $\begin{array}{c}\text { Memory } \\
\text { Aspect }\end{array}$ & $\begin{array}{c}\text { Physical } \\
\text { Aspect }\end{array}$ & $\begin{array}{c}\text { Social } \\
\text { Aspect }\end{array}$ & $\begin{array}{c}\text { Sensory } \\
\text { Aspect }\end{array}$ & $\begin{array}{c}\text { Memory } \\
\text { Aspect }\end{array}$ \\
\hline \multirow{3}{*}{ Local } & Pearson Correlation & -0.157 & 0.000 & 0.175 & $0.445^{* *}$ & -0.236 & 0.040 & 0.149 & 0.270 \\
\hline & Sig.(2-tailed) & 0.286 & 0.998 & 0.234 & 0.002 & 0.107 & 0.786 & 0.312 & 0.063 \\
\hline & $\mathrm{N}$ & 48 & 48 & 48 & 48 & 48 & 48 & 48 & 48 \\
\hline \multirow{3}{*}{ Non-local } & Pearson Correlation & 0.157 & 0.000 & -0.175 & $-0.445 * *$ & 0.236 & -0.040 & -0.149 & -0.270 \\
\hline & Sig.(2-tailed) & 0.286 & 0.998 & 0.234 & 0.002 & 0.107 & 0.786 & 0.312 & 0.063 \\
\hline & $\mathrm{N}$ & 48 & 48 & 48 & 48 & 48 & 48 & 48 & 48 \\
\hline
\end{tabular}

** Correlation is significant at the 0.01 level (2-tailed).

\section{Discussion}

This study has undertaken an exploration of the current knowledge in landscape identity against the background of emergent concerns over loss of landscape identity in approaches to Chinese city development. In particular, the paper focuses on the formation of a new concept of landscape identity relevant to this context. The results from the methodology provided two main findings in relation to the research aim: one is the development of a provisional conceptual framework of landscape identity from the literature to suit the context of Chinese urban development; the second is the insight it can potentially deliver, in terms of landscape identity in the Chinese context. 


\subsection{Conceptual Framework Development}

The conceptual framework can only be considered provisional until it has been tested in the field, and so a study based on interviews has been developed and applied to provide an initial test. This test has enabled the conceptual framework and its operational method to be refined in the following ways:

- The data obtained in the field work of this study were all adapted to the four aspects of the framework. This shows the potential of the conceptual framework in terms of helping to investigate landscape identity with regard to the Chinese context.

- Rather than consider each aspect of the new conceptual framework separately, the study shows how to consider the relationships between aspects so that they provide more meaningful explanations to local landscape identity.

- The study shows a new way to investigate all four aspects of landscape identity together. For example, how each identified location has expressed its power in terms of the four aspects, and how they affect each other.

- Through the interview process the conceptual framework was further refined to be understood by the participants, so they could meaningfully engage with the concept during the interview process.

\subsection{Reflection and Application of Landscape Identity in the Chinese Context}

The overall assessment table clearly shows that the top ten landscape identity elements have the majority of the selections. Each of these elements has its own focus in terms of the landscape identity aspects. For example, Binhai Square is the most recognisable landscape identity element at the study site, and the chart shows that its social aspect representation power takes the majority of the area. The sea is ranked second and has the sensory element chosen as its major presenting form. Also, Zhangyu Wine Cultural Museum occupies a big part of people's memory. It is obvious that in the top ten landscape identities, the majority of the overall selection quantities comprise social aspects, which implies that the study site's landscape identity focusses on its social aspects; it has more meaning to the people because of the activities they have carried out at the local site. Simultaneously, cultural and sensory aspects also affect the local landscape identity.

Moreover, it is explicitly shown by the overall assessment of landscape identity that the major negative feelings that people have toward the landscape identity is with regard to the Physical aspect. This can be observed from the blue section across all the negative charts. Most of the buildings on Haian Street are old or in a state of disrepair, while street pavements, old facilities and grocery shops are poorly managed.

In summary, the representational elements of the different aspects of landscape identity at the study site are all related to its physical locations: the activities that take place on the site, the attractive nightscape and the people's memories of the local history have all become integral parts of the landscape identity. All the sites studied exhibited this interaction between people and the environment that manifests itself in four stages: first, people come to a place in the hope of benefiting from its geographical features; second, the place houses the daily activities and experiences of these users; then people respond to and change the place based on their own iterative requirements; and finally, the timeline of the place and the users evolves, forming the local history and local landscape identity. In the generation of landscape identity, the four aspects mentioned above often interact to drive the evolution.

The findings have to be considered provisional because the conceptual framework is a model in development and more research is needed to refine it further, and because the findings only relate to one case-study area. However, taking these limitations into account, it is reasonable to assume that the insights into landscape identity in the Chinese context may come to focus particularly on the issues below, which could be verified and further developed through more research in different Chinese city contexts:

- Is the conceptual framework applicable to all sites in China?

- For the dynamic feature of landscape identity, how could the conceptual framework reflect the change of identities over time (e.g., summer vs. winter), even on a small scale? 
- Under which circumstances will the interviews generate acceptable results? The site working conditions for this study were sunny weather and an open field of vision. Would adverse weather conditions and a limited visual field affect the interview results?

- Would the conceptual framework generate similar results if the interviews were carried out offsite?

As further research on these issues are addressed, the result is that the gradually improved conceptual framework can be better used to guide designing or decision making. For the former, the proportion of the four aspects enables landscape designers to clearly understand what a place needs to pay attention to in order to keep or create the landscape identity; for the latter, the role of this conceptual framework is more specific: local government is the sole developer of all urban projects in China; hence it is imperative that they adopt appropriate standards to guide their decision in order to protect from the vast loss of landscape identities in the city. The investigation of positive and negative attitudes in the framework can be used to assess the condition of landscape identity, while cluster analysis may be helpful for urban planning and management by looking for more rules of similar places and adopting targeted management methods. Therefore, the definition of landscape identity and its framework can help developers to understand the importance of landscape identity and make them more alert to potential problems when carrying out certain development projects. Otherwise, due to vast inappropriate development, local residents may decide to move out of their own city to seek a better living standard elsewhere. However, the migration of population is affected by more factors, and landscape identity is not decisive. But ignoring it will still bring more adverse effects, such as the loss of intangible cultural heritage.

\section{Conclusions}

This study illustrates landscape identity as an indicator of many physical and spiritual elements, which not only helps to identify the uniqueness of a local place, but also has the potential to enhance the connection between the place and its users. Due to the dynamic nature of the term and a lack of efficient specific identification methods for Chinese urban cities, Chinese cities have suffered a loss of landscape identity in the past. Such a change in landscape has made people feel less attached to their environment and has created an identity crisis in local places in China. In response, this paper delivers a deeper understanding of landscape identity of Chinese urban environments by means of a conceptual framework, with potential for planning and design practice. The conceptual framework of landscape identity is developed in practice in terms of obtaining meaningful data for analysis and is easy to understand by the interview participants. It has also been shown that this conceptual framework shows potential for landscape identity to be further investigated in a typical Chinese city. More importantly, it has the potential to help reveal possible beneficial practices that could be used to enhance the bond between the local environment and its people.

Considering the importance of landscape identity in China, the four-aspects conceptual framework development focuses on the aspects that are most influential and easily observable to people: physical, social, sensory and memory. Although this focus needs to be considered with some caution due to the developmental nature of the conceptual framework, with further research the potential implications for Chinese urban development practice might be to investigate the influential factors relating to local landscape and improve the negative factors, thereby increasing the bond between people and their local environment. Generally, this study concludes that the concept of landscape identity for Chinese urban development and its research requires the employment of a conceptual framework that can be applied in practice to identify and assess landscape identity. The research has shown that the four-aspects concept has the potential to strengthen the understanding of landscape identity in China, offering potential applications in sustainable development of other Chinese urban cities, protecting and improving their landscape identity.

Author Contributions: Conceptualization, Y.S., E.L. and K.T.; methodology, Y.S.; software, Z.X.; validation, Y.S., E.L., K.T., Z.X. and X.X.; formal analysis, Y.S.; investigation, Y.S.; resources, Y.S.; data curation, Z.X.; writing—original draft preparation, Y.S.; writing—review and editing, Y.S. and X.X.; visualization, Z.X.; supervision, 
Y.S., E.L. and K.T.; project administration, Y.S.; funding acquisition, Y.S. All authors have read and agreed to the published version of the manuscript.

Funding: This research and the APC of this paper were funded by National Natural Science Foundation of China (NSFC) “Urban Natural Landscape Visual Comfort Mechanism Research” (No. 51808393).

Acknowledgments: The authors would like to thank all the participants who took part in the interview.

Conflicts of Interest: The authors declare no conflict of interest.

\section{Appendix A. Yantai: One of the Colonised Cities in Recent History of China}

In recent history of China, many cities were colonized, such as Tianjin, Hong Kong and Macao. There had also been Concessions in Shanghai. These colonized cities were either in the northeast, occupied by Japan during World War II, or on the east and south coasts, where convenient shipping supported trade. In 1858, Yantai open as treaty port of Shandong province. Yantai is located in the northeast of Shandong Peninsula, surrounded by the sea on three sides, so the shipping transportation is very convenient. Before the industrial development, the main production activity had been fishing. Later, due to the development of maritime grain transport, Yantai's military importance was enhanced.

One of the signs to measure the modernization of a city is the urban construction. Before Yantai opened, the size of the city was small and the infrastructures were poor, even without a trading market. The prosperity of maritime trade activities accelerated the development of commerce, industry and processing industry, hence new urban areas were increasingly formed. Foreign missionaries, businessmen and government officials came to Yantai one after another; they bought land or "permanently rented" land for the construction of schools, churches, banks and consulates, etc., thus Yantai appeared buildings with modern Western characteristics. Since then, the traditional fishing and agriculture culture, the modern industrial culture and the foreign western culture have all played a role in the urban construction of Yantai. It has been more than a century since the port was opened, foreign western culture, especially the old buildings that can be preserved, has been highly integrated with the old city of Yantai and became physically part of the Yantai's landscape identity. They have been incorporated into the memory of generations of indigenous people and can be perceived as a culture of the city.

Yantai thrived thanks to the development of commerce and industry. However, due to the same location conditions in Shandong Peninsula, other cities such as Qingdao were also developing shipping, which made the competition very fierce. At the start of the 21st century, the old industry began to transform to the new industry, which brought a tough period to Yantai. Up to now, Yantai Development Zone is still exploring the urban regeneration mode with the renovation of old factories as the main measure. Yantai has a regional population of 7.12 million in 2020, while fewer than 5 million live in urban areas. If the urban development is not reasonable, it is bound to be difficult to maintain the population advantage.

\section{References}

1. Creswell, J. Qualitative Inquiry and Research Design: Choosing Among Five Traditions; SAGE Publications: Thousand Oaks, CA, USA, 1998.

2. Jepsen, S.; Harmon, T.C.; Meadows, M.; Hunsaker, C.T. Hydrogeologic influence on changes in snowmelt runoff with climate warming: Numerical experiments on a mid-elevation catchment in the Sierra Nevada, USA. J. Hydrol. 2016, 533, 332-342. [CrossRef]

3. Pedroli, B.; Van Elsen, T.; Van Mansvelt, J. Values of rural landscapes in Europe: Inspiration or by-product? NJAS Wagening. J. Life Sci. 2007, 54, 431-447. [CrossRef]

4. Stephenson, J. The Cultural Values Model: An integrated approach to values in landscapes. Landsc. Urban Plan. 2008, 84, 127-139. [CrossRef]

5. Van Eetvelde, V.; Antrop, M. Analyzing structural and functional changes of traditional landscapes-two examples from Southern France. Landsc. Urban Plan. 2004, 67, 79-95. [CrossRef] 
6. Shannon, M.; Mitchell, C.J. Deconstructing place identity? Impacts of a "Racino" on Elora, Ontario, Canada. J. Rural. Stud. 2012, 28, 38-48. [CrossRef]

7. Vos, W.; Klijn, J. Trends in European Landscape Development: Prospects for a Sustainable Future. In Landscape Ecology to Landscape Science; Klijn, J., Wageningen, V.W., Eds.; Kluwer Academic Publishers; WLO: Dodrecht, The Netherlands, 2000.

8. Antrop, M. Why landscapes of the past are important for the future. Landsc. Urban Plan. 2005, 70, 21-34. [CrossRef]

9. Pinto-Correia, T.; Cancela d'Abreu, A.; Oliveira, R. Landscape Areas in Portugal—Can They Be a Support for Applying Indicators? In Proceedings of the NIJOS/OECD Expert Meeting on Agricultural Landscape, Oslo, Norway, 7-9 October 2002.

10. Kinoshita, I.; Binder, H.; Okabe, A. Identity and Sustainability, Towards New Ways of Urban Redevelopment in an Age of Shrinking Cities; Yasumasa, T., Ed.; Hobunsya Publisher. Inc.: Tokyo, Japan, 2012.

11. Chen, W. The Lack of Innovative Theoratical System in Modern City Construction; Chinese National Ministry of Construction: Beijing, China, 2006.

12. Yu, K. The art of survival: Orientation of contemporary landscape design. J. Arch. 2006, 10, 39-43.

13. Bryce, W.B. Experiences with Chinese City Identity. In Proceedings of the 22nd IAPS Conference, Glasgow, UK, 24-29 June 2012.

14. He, M. Paradigm Shift of Urban Planning Theory in West Countries and Its Implication to China. City Plan. Rev. 2008, 242, 71-77.

15. Yan, G.; Tao, W. The Local identity of modern landscape design. Theory Art Des. 2009, 2, 81-83.

16. Haartsen, T.; Groote, P.; Huigen, P.P.P. Claiming Rural Identities: Dynamics, Contexts, Policies; Van Gorcum: Assen, The Netherlands, 2000.

17. Lynch, K. The Image of the City; MIT Press: Cambdrige, MA, USA; London, UK, 1960.

18. Proshansky, H.M. The City and Self-Identity. Environ. Behav. 1978, 10, 147-169. [CrossRef]

19. Korpela, K. Place-identity as a product of environmental self-regulation. J. Environ. Psychol. 1989, 9, $241-256$. [CrossRef]

20. Cuba, L.; Hummon, D.M. A place to call home: Identification with dwelling, community, and region. Sociol. Q. 1993, 34, 111-131. [CrossRef]

21. Devine-Wright, P.; Lyons, E. Remembering pasts and representing places: The construction of national identities in Ireland. J. Environ. Psychol. 1997, 17, 33-45. [CrossRef]

22. Paasi, A. Region and place: Regional identity in question. Prog. Hum. Geogr. 2003, 27, 475-485. [CrossRef]

23. Jorgensen, A.; Hitchmough, J.; Dunnett, N. Woodland as a setting for housing-appreciation and fear and the contribution to residential satisfaction and place identity in Warrington New Town, UK. Landsc. Urban Plan. 2007, 79, 273-287. [CrossRef]

24. Dixon, J.A.; Durrheim, K. Displacing place-identity: A discursive approach to locating self and other. Br. J. Soc. Psychol. 2000, 39, 27-44. [CrossRef]

25. Quayle, M.; Van Der Lieck, T.C. Growing community: A case for hybrid landscapes. Landsc. Urban Plan. 1997, 39, 99-107. [CrossRef]

26. Ramos, I.L.; Bernardo, F.; Carvalho-Ribeiro, S.M.; Van Eetvelde, V. Landscape identity: Implications for policy making. Land Use Policy 2016, 53, 36-43. [CrossRef]

27. Werner, M.C.; Brown, B.B.; Altman, I. Transactionally Oriented Research: Examples and Strategies. In Handbook of Environmental Psychology; Bechtel, R.B., Churchman, A., Eds.; John Wiley: New York, NY, USA, 2002.

28. Selman, P. Sustainable Landscape Planning; Informa UK Limited: London, UK, 2012.

29. Gualtieri, A.R. Landscape, Consciousness, and Culture. Relig. Stud. 1983, 19, 161-174. [CrossRef]

30. Van Mansvelt, J.D.; Pedroli, B. Landscape-A Matter of Identity and Integrity. In Landscape Series; Palang, H., Fry, G., Eds.; Springer Science and Business Media LLC: Dodrecht, The Netherlands, 2003; pp. 375-394.

31. Schama, S. Landscape and Memory; HarperCollins: London, UK, 1995.

32. Setten, G. The habitus, the rule and the moral landscape. Cult. Geogr. 2004, 11, 389-415. [CrossRef]

33. Olwig, K. Landscape, Nature, and the Body Politic: From Britain's Renaissance to America's New World; University of Wisconsin Press: Madison, WI, USA, 2002.

34. Antrop, M. Landscape change: Plan or chaos? Landsc. Urban Plan. 1998, 41, 155-161. [CrossRef]

35. Wascher, D.M. European Landscape Character Areas: Typologies, Cartography and Indicators for the Assessment of Sustainable Landscapes; Landscape Europe: Wageningen, The Netherlands, 2005. 
36. Palmer, J.; Lankhorst, J.R.-K. Evaluating visible spatial diversity in the landscape. Landsc. Urban Plan. 1998, 43, 65-78. [CrossRef]

37. Mucher, A.S.; Wascher, D. European Landscape Characterization. In Europe's Living Landscapes: Essays Exploring Our Identity in the Countryside; Pedroli, B., van Doorn, A., Wascher, D., Eds.; KNNV: Zeist, The Netherlands, 2007.

38. Locke, J. The Clarendon Edition of the Works of John Locke: An Essay Concerning Human Understanding; Oxford University Press (OUP): Oxford, UK, 1975.

39. Hume, D. David Hume: A Treatise of Human Nature, 2nd ed.; Oxford University Press (OUP): Oxford, UK, 1978.

40. Williams, B.A.O. Problems of the Self: Philosophical Papers (1956-1971); Cambridge University Press (CUP): Cambridge, UK, 1973.

41. Proshansky, H.M.; Fabian, A.K.; Kaminoff, R. Place-identity: Physical world socialization of the self. J. Environ. Psychol. 1983, 3, 57-83. [CrossRef]

42. Belk, R.W. Possessions and the Extended Self. J. Consum. Res. 1988, 15, 139. [CrossRef]

43. Sack, R.D. The Consumer's World: Place as Context. Ann. Assoc. Am. Geogr. 1988, 78, 642-664. [CrossRef]

44. Oktay, D. Urban spatial patterns and local identity: Evaluation in a cypriot town. Open House Int. 1998, 233, $17-23$.

45. Krause, C.L. Our visual landscape: Managing the landscape under special consideration of visual aspects. Landsc. Urban Plann. 2001, 54, 239-254. [CrossRef]

46. Buijs, A.; Pedroli, B.; Luginbühl, Y. From Hiking Through Farmland to Farming in a Leisure Landscape: Changing Social Perceptions of the European Landscape. Landsc. Ecol. 2006, 21, 375-389. [CrossRef]

47. Jacobs, M. The Production of Mindscapes: A Comprehensive Theory of Landscape Experience. Ph.D. Thesis, Wageningen University, Wageningen, The Netherlands, 2006.

48. Stobbelaar, D.J.; Pedroli, B. Perspectives on Landscape Identity: A Conceptual Challenge. Landsc. Res. 2011, 36, 321-339. [CrossRef]

49. Stobbelaar, J.D.; Hendriks, K. Reading the Identity of Place. In Multiple Landscape: Merging Past and Present in Landscape Planning; Wageningen University: Wageningen, The Netherlands, 2004.

50. Korpela, K.; Hartig, T. Restorative qualities of favorite places. J. Environ. Psychol. 1996, 16, $221-233$. [CrossRef]

51. Pretty, G.H.; Chipuer, H.M.; Bramston, P. Sense of place amongst adolescents and adults in two rural Australian towns: The discriminating features of place attachment, sense of community and place dependence in relation to place identity. J. Environ. Psychol. 2003, 23, 273-287. [CrossRef]

52. Breakwell, G.M. Coping with Threatened Identities; Methuen: London, UK, 1986.

53. Twigger-Ross, C.L.; Uzzell, D. Place and identity processes. J. Environ. Psychol. 1996, 16, 205-220. [CrossRef]

54. Wester-Herber, M. Underlying concerns in land-use conflicts-the role of place-identity in risk perception. Environ. Sci. Policy 2004, 7, 109-116. [CrossRef]

55. Stewart, W.P.; Liebert, D.; Larkin, K.W. Community identities as visions for landscape change. Landsc. Urban Plan. 2004, 69, 315-334. [CrossRef]

56. Jorgensen, B.S.; Stedman, R.C. A comparative analysis of predictors of sense of place dimensions: Attachment to, dependence on, and identification with lakeshore properties. J. Environ. Manag. 2006, 79, 316-327. [CrossRef]

57. Kim, J.; Kaplan, R. Physical and psychological factors in sense of community: New urbanist kentlands and nearby orchard village. Environ. Behav. 2004, 36, 313-340. [CrossRef]

58. Antrop, M. Background concepts for integrated landscape analysis. Agric. Ecosyst. Environ. 2000, 77, 17-28. [CrossRef]

59. Kaplan, R.; Kaplan, S. The Experience of Nature: A Psychological Perspective; CUP Archive: Cambridge, UK, 1989.

60. Stobbelaar, J.D.; Hendriks, K. Reading the Identity of Place. In Proceedings of the Multiple Landscape Conference, Wageningen, The Netherlands, 7-9 June 2004.

61. Tajfel, H. Differentiation Between Social Groups: Studies in the Social Psychology of Intergroup Relations; Academic Press: London, UK, 1978.

62. Zube, E.H. Environmental psychology, global issues, and local landscape research. J. Environ. Psychol. 1991, 11, 321-334. [CrossRef]

63. Low, S.M.; Altman, I. Place Attachment; Springer Science and Business Media LLC: Dodrecht, The Netherlands, 1992; pp. 1-12. 
64. Stedman, R.C. Is It really just a social construction? The contribution of the physical environment to sense of place. Soc. Nat. Resour. 2003, 16, 671-685. [CrossRef]

65. Hidalgo, M.; Hernandez, B. Place attachment: Conceptual and empirical questions. J. Environ. Psychol. 2001, 21, 273-281. [CrossRef]

66. Stedman, R.C. Toward a social psychology of place: Predicting behavior from place-based cognitions, attitude, and identity. Environ. Behav. 2002, 34, 561-581. [CrossRef]

67. Jacobs, J. The Death and Life of Great American Cities; Penguin in association with Jonathan Cape; Penguin Books: Harmondsworth, UK, 1994.

68. Carr, S. Public Space; Cambridge University Press: Cambridge, UK, 1992.

69. Carmona, M. Public Places Urban Spaces: The Dimensions of Urban Design; Taylor \& Francis-M.U.A. Ltd.: Leiden, The Netherlands, 2003.

70. Oktay, D. How Can Urban Context Maintain Urban Identity and Sustainability? Evaluations of Taormina (Sicily) and Kyrenia (North Cyprus). In Proceedings of the International Conference for Integrating Urban Knowledge and Pactice, Gothenburg, Sweden, 30 May-4 June 2005.

71. Halbwachs, M. Les Cadres Sociaux De La Mémoire; Presses Universitaires de France: Paris, France, 1925.

72. Zerubaveled, T. Book Review: Time Maps: Collective Memory and the Social Shape of the Past; The University of Chicago Press: Chicago, IL, USA, 2003.

73. Mesch, G.S.; Manor, O. Social Ties, Environmental Perception, And Local Attachment. Environ. Behav. 1998, 30, 504-519. [CrossRef]

74. Association, Yantai History Research. The History of Yantai; Yantai History Research Association Press: Yantai, China, 1990.

75. Lindberg, K.; Veisten, K. Local and non-local preferences for nature tourism facility development. Tour. Manag. Perspect. 2012, 4, 215-222. [CrossRef]

76. Durrant, J.O.; Shumway, J.M. Attitudes Toward Wilderness Study Areas: A Survey of Six Southeastern Utah Counties. Environ. Manag. 2004, 33, 271-283. [CrossRef] [PubMed]

77. Kennedy, E.H.; Beckley, T.M.; McFarlane, B.L.; Nadeau, S. Rural-Urban Differences in Environmental Concern in Canada. Rural Sociol. 2009, 74, 309-329. [CrossRef]

78. Hernandez, B.; Hidalgo, M.C.; Salazar-Laplace, M.E.; Hess, S. Place attachment and place identity in natives and non-natives. J. Environ. Psychol. 2007, 27, 310-319. [CrossRef]

79. Kelly, G.J.; Hosking, K. Nonpermanent Residents, Place Attachment, and "Sea Change" Communities. Environ. Behav. 2008, 40, 575-594. [CrossRef]

80. Shinebourne, P. Using Q Method in Qualitative Research. Int. J. Qual. Methods 2009, 8, 93-97. [CrossRef]

81. Watts, S.; Stenner, P. Doing Q ethodology: Theory, method and interpretation. Qual. Res. Psychol. 2005, 2, 67-91. [CrossRef]

82. Boehmke, B.; Greenwell, B.M. Hands-On Machine Learning with R; Informa UK Limited: London, UK, 2019.

83. Ward, J.J.H., Jr. Hierarchical Grouping to Optimize an Objective Function. J. Am. Stat. Assoc. 1963, 58, 236-244. [CrossRef]

(C) 2020 by the authors. Licensee MDPI, Basel, Switzerland. This article is an open access article distributed under the terms and conditions of the Creative Commons Attribution (CC BY) license (http://creativecommons.org/licenses/by/4.0/). 